\title{
Introduction to this Special Issue on the Evolution of Material Culture
}

\author{
Anna Marie Prentiss
}

Published online: 22 July 2011

(C) Springer Science+Business Media, LLC 2011

Scholars have been interested in the history of material culture for centuries, addressing change in artifacts from a wide variety of standpoints including art history, symbolism, and culture history. Artifacts, in these contexts, marked change in the lives of artists, practices and beliefs of the literary and artistic class, and cultural traditions of entire populations (Schlereth 1999). It has only been in recent decades that scholars have initiated rigorous studies of material cultural evolution using Darwinian evolutionary theory. Darwinian analysis of material culture has faced an uphill battle on several fronts. One critical factor was an explicit rejection of Darwinian thinking among prominent anthropologists of the early twentieth century (e.g. Kroeber 1931). Culture historians in the middle decades in the twentieth century generally relied upon a paradigm designed to provide descriptive accounts of artifact inventories as normative markers of particularistic cultural traditions, but generally did not seek any deeper evolutionary explanations of variability.

During the processual archaeology revolution of the 1960s and 1970s, scholars rejected idiosyncratic history in favor of a covering law model of explanation (Watson et al. 1984). Artifacts were now interpreted not so much as cultural standards but as indicators of functioning cultural systems. In his now-classic work Archaeology as Anthropology (1962), Lewis Binford classified artifacts as technomic, sociotechnic, and ideotechnic, referring to the roles of items, respectively, in technological, social, and ideological sub-systems. The post-processual paradigm in archaeology, initiated during the

\footnotetext{
A. M. Prentiss $(\bowtie)$

Department of Anthropology, The University of Montana,

Missoula, MT 59812, USA

e-mail: anna.prentiss@mso.umt.edu
}

1980s, rejected the systems view and covering law model of the processualists and sought to replace it with a return to an interest in history and artifact as a symbol of socioideological context and cultural practice (Hodder 1982; Watson and Fotiadis 1990). Neither the processualist nor post-processualist theoretical schools advocated Darwinian analysis in archaeology despite their intense interests in artifacts. An evolutionary theory in artifact studies would have to come from another direction.

The stage was set for a Darwinian approach to material culture, not from within archaeology, but from disciplines as diverse as evolutionary biology, paleontology, and evolutionary cultural anthropology. Few would disagree that this began with the Neo-Darwinian Synthesis of the 1940s and 1950s in which Mendelian inheritance and Darwinian natural selection were combined to create a comprehensive theory of evolution. This gave new life to paleontology as a science of long-term evolutionary process (Simpson 1944), eventually termed "paleobiology" (e.g., Gould 1980). Phylogenetic analysis took on a new importance as not just a way to catalogue the panoply of life but as a means of understanding macroevolutionary process. It was not long before scholars interested in material cultural phenomena took notice.

As early as the 1960s, anthropologists began to think about culture as an inheritance system analogous to that of biology (e.g., Campbell 1965). Dawkins' (1976) concepts of the meme and extended phenotype provided a name for a unit of cultural inheritance and at least a partial justification for viewing cultural evolution within a biological framework. Works by Boyd and Richerson (1985), Cavalli-Sforza and Feldman (1981), and Durham (1991) established so-called transmission or coevolution theory with its emphasis on microevolutionary processes of communication, emulation, and human behavior. At roughly the same 
time, a small group of archaeologists sought to construct a neo-Darwinian approach known as evolutionary archaeology or selectionism to explain artifact histories on a more macroevolutionary scale (O'Brien 1996 and papers therein; O'Brien and Lyman 2000). A wide range of scholars have subsequently sought to apply evolutionary logic and phylogenetic methods to a more divergent range of cultural characters ranging from artifacts to language (e.g., Lipo et al. 2006; Mace et al. 2005).

As the contributions in this special issue illustrate, evolutionary study of material culture is alive and well today. Indeed, there a several schools of thought with both common and divergent assumptions about the nature of the cultural evolutionary process. For purposes of discussion, I divide them into four groups: Strict Neo-Darwinists (SND), Transmission Theorists (TT), Extended Darwinists (ED), and Darwinian Complexity Theorists (DCT). The strict Neo-Darwinians, as best embodied in the evolutionary archaeology school, accept a narrow interpretation of the Darwinian evolutionary model or what has been described as the "Hardened Synthesis" (Brooks 2011; Eldredge 1995). SND scholars (e.g., Dunnell 1989; O'Brien and Lyman 2000) have generally argued that cultural variation is undirected in relation to long-term effects of natural selection, selection acts directly on functional aspects of artifacts when viewed as extended phenotypes, nonfunctional or stylistic elements of artifacts are sorted over time by drift, cultural transmission process is largely superfluous, macroevolution is gradual, and cultural entities are analyst defined.

Transmission Theorists are primarily concerned with microevolutionary process, viewing artifact variation over time as reflections of traditions inherited through communication and emulation. While much of the TT literature derives from mathematical evolutionary anthropology (e.g., Boyd and Richerson 1985, 2005), a limited number of archaeologists have engaged in tests of model predictions using experimental (Mesoudi and O'Brien 2008) and archaeological (Bettinger and Eerkens 1997) data. While TT scholars generally accept the basic neo-Darwinian framework, they seek to understand variability in artifact traditions largely as outcomes of different cultural transmission systems rather than the strict undirected variation, selection, and drift model favored by the SND group. Given their interest in microevolutionary process, they tend to be somewhat less concerned with pattern and process in macroevolution.

Extended Darwinists in material culture studies are most theoretically in line with the "Extended Synthesis" school of evolutionary biology, recognizing that synthetic Darwinism remains incomplete without resurrection of lost concepts and incorporation of critical new ideas (Brooks 2011; Eldredge 1985; Prentiss et al. 2009). ED scholars recognize that targets of evolutionary process can range from artifacts to complexly integrated cultural traditions such as religious beliefs and rituals or subsistence strategies (Mace and Holden 2005; Rosenberg 1994; Spencer 1997). They generally emphasize macroevolutionary process and assume that cultural entities actually exist with approximate start and extinction dates, the pattern of evolution is often punctuated, transmission and selection play roles in evolutionary process, and spandrels and exaptations are common (Bettinger 2009; Rosenberg 2009).

Darwinian Complexity Theorists employ Darwinian logic to understand the evolution of complex adaptive systems, whether biological as in protein and body plan organization or cultural, for example, software systems (Arthur and Polak 2006; Myers 2003; Solé et al. 2002). Significant concerns among these researchers are the processes that give rise to new entities with differentially integrated modular parts. Consequently, these scholars make a contribution to understand the nature of evolutionary hierarchies (e.g., Eldredge 1985) and much like the ED school seek to understand periods of rapid evolutionary change using such models and concepts as spandrels, adaptive landscapes, and phylogenetic history.

Research and discussion among evolutionary material culture scholars has already created a rich body of literature and has stimulated a range of insights. Contributors to the special issue offer a number of provocative contributions that should continue to stir debate and further studies. I highlight six critical points.

\section{Phylogeny is Essential to Explanation}

Preexisting structural properties of artifacts affect future evolution. Phylogenetic studies suggest support for Brooks' (2011:6) argument that the "nature of the organism" may be more important to evolution than the associated conditions. Prentiss et al. point out that, in the case of skateboards, severe design constraints restricted designers to a relatively narrow range of modifications even when their expected use-environments were radically different. Dagg argues that mousetrap evolution was dependent on independent evolution of constituent parts. Solé et al. note that use of preexisting elements in complex networks could act as strong constraints on evolution. These studies offer the implication that significantly greater attention should be placed on artifact phylogeny and ontogeny (e.g., manufacture, use, maintenance, recycling) as we theorize evolutionary process. Phylogenetic methods have also offered material culture scholars (particularly archaeologists) highly rigorous procedures 
for identifying critical variables for measuring artifact variability and evolutionary history.

\section{Artifacts Evolve via Branching}

Branching signatures are recognized in quantitative study of skateboards (Prentiss et al.) and Iranian textiles (Tehrani). These results are similar to outcomes of other phylogenetic studies (e.g. Jordan and Shennan 2009) and contradict assertions made elsewhere in anthropology and archaeology that cultural evolution is primarily reticulate in nature (Moore 1994; Sassaman 2011). If branching is indeed common then it is appropriate to ask how it works. Several contributors (particularly Dagg and Solé et al.) implicate "tinkering" as critical to branching in technological evolution. They provide evidence that major jumps in a range of technologies happen as makers "tinker" with available designs and materials, a process similar to the actions of natural selection on organisms. Solé et al. point out that if material culture evolves in this way then we can expect spandrels (e.g., Gould and Lewontin 1979) to be common. Solé et al. also note that minor tinkering can sometimes lead to "avalanches of modifications" and patterns of punctuated equilibria. In an interesting sideline, Dagg suggests that borrowing processes may in some cases actually contribute to reconfigured designs and thus lead to branching events. "Popsicle stick" skateboard designs provide a good example of this process.

\section{Artifact Evolution is Reticulated}

Artifact lineages can include branching and reticulation. Prentiss et al. demonstrate that while the history of skateboard manufacture is rife with homoplasy (e.g., lateral transfer through borrowing) and possibly also tokogenetic processes (independent invention and character reversals), there is an underlying branching structure to the phylogenetic trees. In contrast to biology, the frequency of lateral transfer seems to rise with the appearance of the greatest diversity of design variants. These results confirm arguments by Eldredge (2009) and Tëmkin and Eldredge (2007) that cultural evolution is extraordinarily complex, requiring significant caution by those seeking to construct simple phylogenetic models. This research also confirms the cautionary statements of Kroeber (1931) and Sassaman (2011) regarding reticulations. And yet, Tehrani informs us that branching in some lineages may be significantly stronger than lateral transfer via borrowing. One cause for branching can be geographic and social isolation as was the case for Iranian tribal women engaged in textiles production, and as acknowledged by Sassaman (2011) for branching in Paleoindian technologies at the PleistoceneHolocene boundary in North America.

\section{Natural Selection is Often Metaphorical in Artifact Microevolution}

Artifact evolutionists must be careful in their use of the term "selection" since they are not typically discussing change over time in alleles but in memes that code for particular artifact designs. Designs that are replicated frequently can be said to have high degrees of "replicative success" (Leonard and Jones 1987) or "acquisitive fitness" (Chatters 2009). But replicative success and acquisitive fitness do not necessarily require reproductive fitness from a biological standpoint. Skateboards evolved in a branching process at rates far too fast to be associated with biological reproductive success and arguably, were tools virtually guaranteed to reduce the probability of the user ever making a significant contribution to the gene pool. Rapid turnovers in the design of mousetraps and software have similar implications (though lacking the life-threatening element inherent in skateboards). However, there are examples of artifact evolution where one could consider roles for acquisitive and biological fitness. As suggested by Goodale et al., it is entirely possible that possession of certain weapon systems (e.g., bow and arrow) by Native American groups across the Holocene may have imparted significant advantages in hunting and warfare. Indeed, Chatters (2009) argues that the bow and arrow system as an evolutionary entity offered such fitness advantages to indigenous groups that it outlasted many other technologies and resource management strategies. Archaeologists have yet to determine the actual rates and processes by which the bow and arrow spread across Native North America at around 1,500 to 2,500 years ago. This leaves open the possibility that it was a very rapid process (say less than 300 years), probably too fast to invoke natural selection (in the narrow biological sense), thus implying replicative success and acquisitive fitness. On the other hand, if the process took longer (for example, 500 to 1,000 years) and was associated with differential group advantage between those with and those without, then, following Soltis et al. (1995), cultural group selection could be offered as an explanatory model, thereby allowing a role for biological fitness.

\section{Artifacts Do Not Evolve Independent of Other Cultural Characters}

Several years ago Holden and Shennan (2005) rejected the "cultures as collections of memes" position, arguing that the persistence of languages and complex cultural traditions 
negates the possibility that memes or basic units of cultural information exist in competitive isolation from one another. Eldredge (2009) argued that not only are cultural traditions bundled in complex ways, but their persistence often depends on relationships to other cultural developments such that simple functional performance does not guarantee replicative success. Many technologies from mousetraps to software systems are made up of multiple interacting parts. Evolution of these entities can be dependent on changes in the nature of the parts and the ways in which they are fit together. Skateboard evolution was clearly affected by innovations in board design, but was equally impacted by developments outside the latter domain. Urethane wheels enhanced rider safety and enabled significant improvement in the ability of riders to negotiate spillway slopes and empty swimming pool walls. Wider cultural factors also played significant roles. The "bust" period in skateboard history of ca. 1990 to 1995 led to widespread abandonment of wall riding on ramps and in empty pools, but favored the widespread adoption of street skating and in particular the popular rise of the trick known as "Ollies" for "popping" on to stair railings, on and off benches and tables, and up curbs without grabbing the rail of the board. This favored the development of the "popsicle stick" design with its double kicktails and convex board shape (see Prentiss et al. this issue). Changes in the design of Barbie dolls, as outlined by Goodale et al., likewise reflect the changing milieu of popular culture in western countries. Material cultural researchers should continue to address correlated change in items of material culture within their wider cultural context (Bettinger 2009; Eldredge 2009).

\section{Artifact Evolution Needs a Grand Theory}

In a recent issue of this journal, Brooks (2011) promoted development of a higher covering law linking biology to the other sciences. Michael Shott in this issue, like Brooks, also calls for evolutionary scholars to think deeply about their target material. Shott points to a number of unique factors affecting variability in material culture, in this case stone tools, as expressed in the archaeological record. $\mathrm{He}$ points to the complexity inherent in cultural transmission processes and the difficulty involved in recognizing the effects of different transmission regimes, noting the high probability in many cases of equifinality in outcomes. He asks, what other cultural and environmental factors could affect the formation of lineages and proposes that scholars consider effects of variability in numbers of human artifact makers, raw materials, and environmental conditions. He, like others in this issue, suggests that artifact ontogeny may affect our constructions of phylogeny. Finally, Shott reminds us that tool production and use do not reside outside the confines of their associated cultural matrices. A grand theory of artifact evolution must offer linkages between all of these contributing elements and if truly within the vision offered by Brooks (2011), it would strengthen the bond between the science of artifact evolution and a wider range of disciplines. Perhaps we are not quite there yet, but the contributions in this issue help to take us down that road.

Acknowledgments I thank Niles and Greg Eldredge for inviting me to guest edit the special issue of Evolution: Education and Outreach on material cultural evolution. Niles has been a wonderful research partner and sounding board as we moved through the research and editing process. Next, I thank all contributors to this issue for their thoughtful contributions and good-natured acceptance of peer-review and editor's comments. Finally, I thank Randy Skelton and Niles Eldredge for their comments on this short paper.

\section{References}

Arthur B, Polak W. The evolution of technology within a simple computer model. Complexity. 2006;11:23-31.

Bettinger RL. Macroevolutionary theory and archaeology: is there a big picture? In: Prentiss AM, Kuijt I, Chatters JC, editors. Macroevolution in human prehistory: evolutionary theory and processual archaeology. New York: Springer; 2009. p. 27596.

Bettinger RL, Eerkens J. Evolutionary implications of metric variation in great basin projectile points. In: Barton CM, Clark GA, editors. Rediscovering Darwin: evolutionary theory and archaeological explanation. Washington: American Anthropological Association, Archeological Papers No. 7; 1997. p. 177-91.

Binford LR. Archaeology as anthropology. Am Antiq. 1962;28:21725.

Boyd R, Richerson PJ. Culture and the evolutionary process. Chicago: University of Chicago Press; 1985.

Boyd R, Richerson PJ. The origin and evolution of cultures. Oxford: Oxford University Press; 2005.

Brooks DR. The extended synthesis: something old, something new. Evolution: Education and Outreach. 2011;4:3-7.

Campbell DT. Variation and selective retention in sociocultural evolution. In: Barringer HR, Blanksten GI, Mack RW, editors. Social change in developing areas: a reinterpretation of Evolutionary Theory. Cambridge: Schenkman; 1965. p. 19-49.

Cavalli-Sforza LL, Feldman MW. Cultural transmission and evolution: a quantitative approach. Princeton: Princeton University Press; 1981.

Chatters JC. A macroevolutionary perspective on the archaeological record of North America. In: Prentiss AM, Kuijt I, Chatters JC, editors. Macroevolution in human prehistory: evolutionary theory and processual archaeology. New York: Springer; 2009. p. 21334.

Dawkins R. The selfish gene. Oxford: Oxford University Press; 1976.

Dunnell RC. Aspects of the application of evolutionary theory in archaeology. In: Lamberg-Karloffsky CC, editor. Archaeological thought in America. Cambridge: Cambridge University Press; 1989. p. 35-49.

Durham WH. Coevolution: genes, culture, and human diversity. Stanford: Stanford University Press; 1991.

Eldredge N. Unfinished synthesis: biological hierarchies and modern evolutionary thought. New York: Oxford University Press; 1985. 
Eldredge N. Reinventing Darwin: the great debate at the high table of evolutionary theory. New York: Wiley; 1995.

Eldredge N. Material cultural macroevolution. In: Prentiss AM, Kuijt I, Chatters JC, editors. Macroevolution in human prehistory: evolutionary theory and processual archaeology. New York: Springer; 2009. p. 297-316.

Gould SJ. The promise of paleobiology as a nomothetic, evolutionary discipline. Paleobiology. 1980;6:96-118.

Gould SJ, Lewontin RC. The spandrels of San Marco and the Panglossian paradigm: a critique of the adaptationist programme. Proceedings of the Royal Society of London B. 1979;205:581-98.

Hodder I. Symbolic and structural archaeology. Cambridge: Cambridge University Press; 1982.

Holden CJ, Shennan S. Introduction to part 1: how tree-like is cultural evolution? In: Mace R, Holden CJ, Shennan S, editors. The evolution of cultural diversity: a phylogenetic approach. London: UCL Press; 2005. p. 11-29.

Jordan P, Shennan S. Diversity in hunter-gatherer technological traditions: mapping trajectories of cultural 'descent with modification' in Northeast California. J Anthropol Archaeol. 2009;28:342-65.

Kroeber AL. Historical reconstruction of historical growths and organic evolution. Am Anthropol. 1931;33:149-56.

Leonard RD, Jones GT. Elements of an inclusive evolutionary model for archaeology. J Anthropol Archaeol. 1987;6:199-219.

Lipo CL, O'Brien MJ, Collard M, Shennan S, editors. Mapping our ancestors: phylogenetic approaches in anthropology and history. New Brunswick: Aldine/Transaction; 2006.

Mace R, Holden CJ. A Phylogenetic approach to cultural evolution. Trends Ecol Evol. 2005;20:116-21.

Mace R, Holden CJ, Shennan S. The evolution of cultural diversity: a phylogenetic approach. London: UCL Press; 2005.

Mesoudi A, O'Brien MJ. The cultural transmission of great basin projectile point technology: an experimental simulation. Am Antiq. 2008;73:3-28.

Moore JH. Putting anthropology back together again: the ethnogenetic critique of cladistic theory. Am Anthropol. 1994;96:925-48.

Myers CE. Software systems as complex networks: structure, function, and evolvability of software collaboration graphs. Physical Review E. 2003;68:046116.
O'Brien MJ, editor. Evolutionary archaeology: theory and application. Salt Lake City: University of Utah Press; 1996.

O'Brien MJ, Lyman RL. Applying evolutionary archaeology: a systematic approach. New York: Kluwer Academic/Plenum Press; 2000.

Prentiss AM, Kuijt I, Chatters JC, editors. Macroevolution in human prehistory: evolutionary theory and processual archaeology. New York: Springer; 2009.

Rosenberg M. Pattern, process, and hierarchy in the evolution of culture. J Anthropol Archaeol. 1994;13:307-40.

Rosenberg M. Proximate causation, group selection, and the evolution of hierarchical human societies: system, process, and pattern. In: Prentiss AM, Kuijt I, Chatters JC, editors. Macroevolution in human prehistory: evolutionary theory and processual archaeology. New York: Springer; 2009. p. $23-50$.

Sassaman KE. History and alterity in the eastern archaic. In: Sassaman KE, Holly DH, editors. Hunter-gatherer archaeology as historical process. Tucson: University of Arizona Press; 2011. p. 187-208.

Schlereth T. Material culture studies. New York: Altamira; 1999.

Simpson GG. Tempo and mode in evolution. New York: Columbia University Press; 1944.

Solé RV, Ferrer i Cancho R, Montoya JM, Valverde S. Selection, tinkering, and emergence in complex networks. Complexity. 2002;8:20-33.

Soltis J, Boyd R, Richerson PJ. Can group functional behaviors evolve by cultural group selection? An empirical test. Curr Anthropol. 1995;36:473-94.

Spencer CS. Evolutionary approaches in archaeology. J Archaeol Res. 1997;5:209-64.

Tëmkin I, Eldredge N. Phylogenetics and material cultural evolution. Curr Anthropol. 2007;48:146-54.

Watson PJ, Fotiadis M. The Razor's edge: symbolic-structuralist archeology and the expansion of archeological inference. Am Anthropol. 1990;92:613-29.

Watson PJ, LeBlanc SA, Redman CL. Archeological explanation: the scientific method in archaeology. New York: Columbia University Press; 1984. 